Hydrological Research Letters, 4, 15-19 (2010)

Published online in J-STAGE (www.jstage.jst.go.jp/browse/HRL). DOI: 10.3178/HRL.4.15

\title{
Projection of Extreme Wave Climate Change under Global Warming
}

\author{
Nobuhito Mori ${ }^{1}$, Tomohiro Yasuda ${ }^{1}$, Hajime Mase ${ }^{1}$, Tracey Tom ${ }^{1,2}$, and Yuichiro Oku ${ }^{1}$ \\ ${ }^{1}$ Disaster Prevention Research Institute, Kyoto University, Kyoto, Japan \\ ${ }^{2}$ Surflegend Co. Ltd., Fujisawa, Japan
}

\begin{abstract}
:
The influence of global climate change due to greenhouse effects on the earth's environment will require impact assessment, mitigation and adaptation strategies for the future of our society. This study predicts future ocean wave climate in comparison with present wave climate based on the atmospheric general circulation model and global wave model. The annual averaged and extreme sea surface winds and waves are analyzed in detail. There are clear regional dependences of both annual average and also extreme wave height changes from present to future climates. The wave heights of future climate will increase at both middle latitudes and also in the Antarctic Ocean, with a decrease at the equator.
\end{abstract}

KEYWORDS global warming; climate change; ocean wave; wave height; sea surface wind

\section{INTRODUCTION}

Research of global climate change due to greenhouse effects on the earth's environment is changing from understanding phenomena to impact assessment, mitigation and adaptation strategies for future development of human society. Sea-level rise has been observed at a rate of $1.7 \mathrm{~mm}$ $\pm 0.3 \mathrm{~mm} / \mathrm{yr}$ from 1870 to 2004 and a significant acceleration of sea-level rise was observed in the last ten years (Church and White, 2006). The major source of the sea-level rise is thermal expansion of sea water temperature increase, thus the sea-level rise is a static side issue of climate change influence. Sea-level rise greatly impacts human activity near the coastal zone (IPCC, 2007) and simply exacerbates the vulnerability of coastal regions to other physical processes (e.g. storm surges, storm waves). Another direct influence of sea-level rise is the inundating of low level coastal areas which is of concern.

On the other hand, ocean waves and storm surges of future climate are also expected to change characteristics from the present climate and are the dynamic side issue of climate change. It is necessary to seriously consider the impacts of these dynamic phenomena for coastal disaster prevention and reduction, if extreme weather events will become stronger than those in the present climate. For example, the North Atlantic observed wave data shows 5 $\mathrm{cm} / \mathrm{yr}$ increase of annual maxima for the last 40 years (Wang and Swail, 2002). The wave hindcasts in the Atlantic Ocean show more significant wave height increase in the region off the Canadian coast and the northwest of Ireland but less significant change in the North Sea and in the region off the Scandinavian coast (Wang and Swail, 2002). In addition, long-term changes of storm waves and surges are important for infrastructures near the coastal zone. For example, a coastal breakwater design is basically determined by the wave pressure of the maximum wave condition, the so-called design wave, for durable period and the wave pressure is proportional to the wave height. Moreover, coastal erosion is another critical issue, where more than $70 \%$ of sandy beaches around the world are presently erosional. Equilibrium condition of coastal beach profile depends on seasonal or annual wave height, period and direction. The projection of future change on coastal erosion is insufficient due to information deficiencies on changes in waves and coastal currents. Therefore, future ocean wave climate change will have significant impacts on extreme and daily coastal environments. These influences will be at greatest risk at coastal areas, especially in the heavily populated mega delta regions of East, South-East and South Asia. The future coastal environmental changes give a big influence to these regions, directly.

The future wave climate projection has been conducted by a few researchers (e.g. Hemer et al., 2006). These studies have shown an increase in wave height due to increased wind speeds associated with mid-latitude storms in many regions of the mid-latitude oceans. Zhang et al. (2004) and Wang and Swail (2006) made statistical projections of global wave height from the empirical relationships between sealevel pressure and significant wave height. Furthermore, the dynamical regional wave climate projections has been carried out in Europe and North America but there is no dynamical global wave climate projection at present.

This study projects future wave climate and analyzes differences between present and future ocean wave climate models based on the high-resolution atmospheric General Circulation Model (GCM) developed by the Japanese Meteorological Research Institute and Japan Meteorological Agency (MRI-JMA) and the global wave model. The averaged and extreme ocean wave climate changes on both global and regional scales are discussed.

\section{METHOD OF WAVE CLIMATE PROJECTION}

This research uses the product of global climate projections on the basis of $20 \mathrm{~km}$ high-resolution GCM developed by MRI-JMA (denoted by GCM for simplicity hereafter). The $20 \mathrm{~km}$ high-resolution MRI-JMA GCM is the single atmospheric GCM with T959L60 resolution following A1B scenario and is newly developed for the Kakushin (2007) program (Kitoh et al., 2009). The Kakushin 
Table I. Three periods of time-slice experiment

\begin{tabular}{lcc}
\hline Period & Start & End \\
\hline Present climate (SP0A) & Jan. 1979 & Dec. 2003 \\
Near future climate (SN0A) & Jan. 2015 & Dec. 2031 \\
Future climate (SF0A) & Jan. 2075 & Dec. 2099 \\
\hline
\end{tabular}

(2007) program is a Japanese Government supported climate prediction project and one of its objectives is the quantitative prediction of extreme weather around East Asia and Japan. The external forcing of the GCM is sea surface temperature (SST) and the ensemble averaged warmer SST and related oceanic conditions, projected by different coupled atmosphere-ocean GCM runs used in the IPCC AR4 (CMIP3), are used as bottom boundary conditions for the future climate projection, although the observed SST is used in the present climate computation. The time-slice experiments were conducted for the three climate periods of 1979-2004 (present climate), 2015-2031 (near future climate) and 2075-2100 (future climate) following A1B scenario (see Table I). By using the data computed from the GCM, disaster and environmental changes that may lead to natural disasters have been evaluated (i.e. Mori et al., 2009; Yasuda et al., 2009). In this study, we mainly focus on the differences between the present and future climate for both the averaged and extreme wave conditions.

The global wave climate projections for the three periods were simulated by the SWAN (Simulating WAves Nearshore) model (Booij et al., 1999) using sea surface wind at $10 \mathrm{~m}$ height $U_{10}$ of the GCM. The global wave computations were carried out using a spherical coordinate in the latitude range of $80^{\circ} \mathrm{N}-80^{\circ} \mathrm{S}$ with 1.25 degree resolution $(289 \times 126$ grids $)$. The wave statistics such as significant wave height $H_{s}$, wave period $T_{s}$ and others were archived every 1 hour for three periods. The long-term wave climate changes were analyzed both for the global scale and regional oceans.

The computed wave projection was verified by the longterm observed data. Over 25 years of observation data in the Pacific Ocean were selected for the validation. Figure 1 shows an example of comparison of $H_{S}$ between the present climate run and NDBC buoy data offshore of Alaska. Although the peak of $H_{s}$ in present climate is slightly smaller than the observed data, the profile of pdf is quite similar. Table II shows statistical summary of comparison of $U_{10}$ and $H_{S}$ between the present climate run and observed data at three different locations in the Pacific Ocean. The averaged mean $H_{S}$ is $11 \%$ underestimated, although the averaged mean $U_{10}$ is $7 \%$ overestimated. On the other hand, the averaged standard deviation of $H_{S}$ is $2.3 \%$ underestimated and the averaged standard deviation $U_{10}$ is $5 \%$ understimated. There is a non-negligible error in the computed wave average, and the computed wave height, therefore, includes same order of error. However, it is possible to estimate the ratio of wave climate change from the present to future climate, quantitatively. The analysis of computed future wave climate change from the present climate will be discussed in the next section.
GCM NOAA Point at Hawaii

(51002)

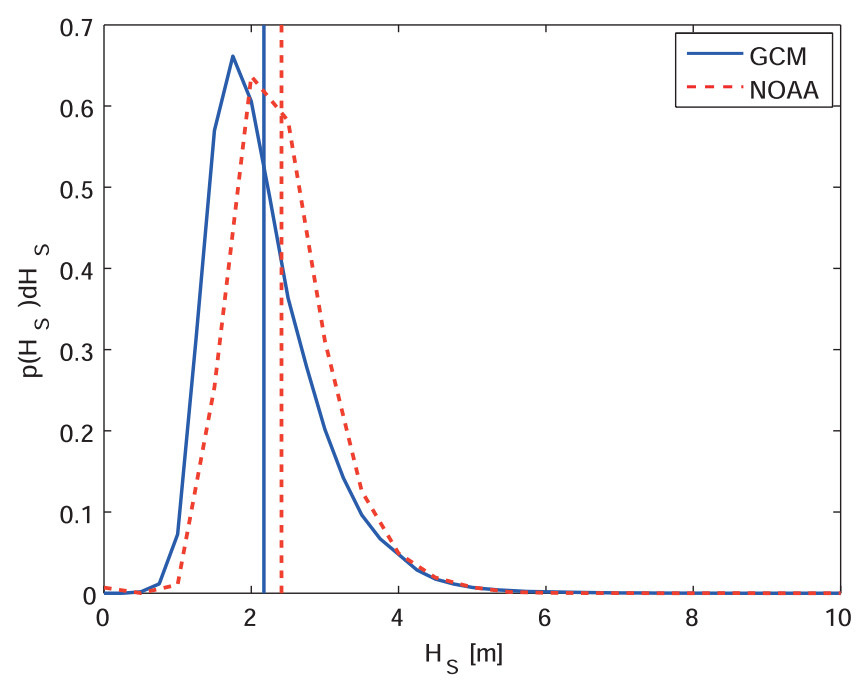

Figure 1. Comparison of $H_{s}$ between present climate result and observed data from offshore of Alaska (NOAA Buoy \#51002)

Table II. Comparison of $U_{10}$ and $H_{S}$ between present climate results and observed data

\begin{tabular}{lccllcc}
\hline$\#$ & \multicolumn{2}{c}{$U_{10}:$ GCM/OBS } & & \multicolumn{2}{c}{$H_{s}:$ WGCM/OBS } \\
\cline { 1 - 2 } \cline { 6 - 7 } Buoy & Mean & Std. & & Mean & Std. \\
\hline $46001(\mathrm{P})$ & 1.126 & 0.808 & & 0.967 & 1.090 \\
$51002(\mathrm{P})$ & 1.076 & 0.969 & & 0.901 & 0.889 \\
$51003(\mathrm{P})$ & 1.010 & 1.073 & & 0.794 & 0.982 \\
\hline Averaged & 1.071 & 0.950 & & 0.887 & 0.987 \\
\hline
\end{tabular}

\section{RESULTS AND DISCUSSION}

\section{Mean wave climate change}

The important characteristics of future projection are not only extreme wave climate but also daily wave climate. Before discussing the extreme wave climate change, the period averaged (mean) $H_{S}$ is first discussed. Figure 2 shows the mean of $H_{s}$ (denotes $\bar{H}_{s}$ hereafter) in the present and future climates (Florida area is excluded for the analysis following validation results). Regarding the differences of $\bar{H}_{s}$ between the present and future climates, there are regional dependencies for $\bar{H}_{s}$ similar to $U_{10}$ (Mori et al., 2009). There are remarkable characteristics of large scale pattern change of averaged $\bar{H}_{S}$ from the present to future climate. First, the small wave height region on the equator is expanded in both north and south directions. On the other hand, the large wave height region in the Antarctic Ocean is expanded from the present to future climate.

Figure 3 shows the normalized difference between the future and present climate (future minus present divided by present). The future $\bar{H}_{S}$ in the Pacific Ocean on the equator will be decreased by about $7 \%$ which corresponds to a 0.1 m decrease in averaged wave height. The future $\bar{H}_{S}$ in the latitude range of $30^{\circ} \mathrm{N}-45^{\circ} \mathrm{N}$ in the North Pacific and the North Atlantic Ocean will be decreased by $7 \%$ which corresponds to $0.15 \mathrm{~m}$ of averaged wave height, 
(a) Present climate

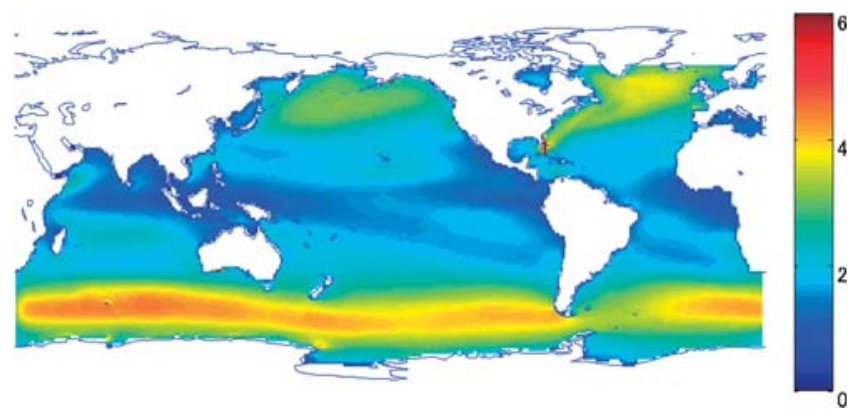

(b) Future climate

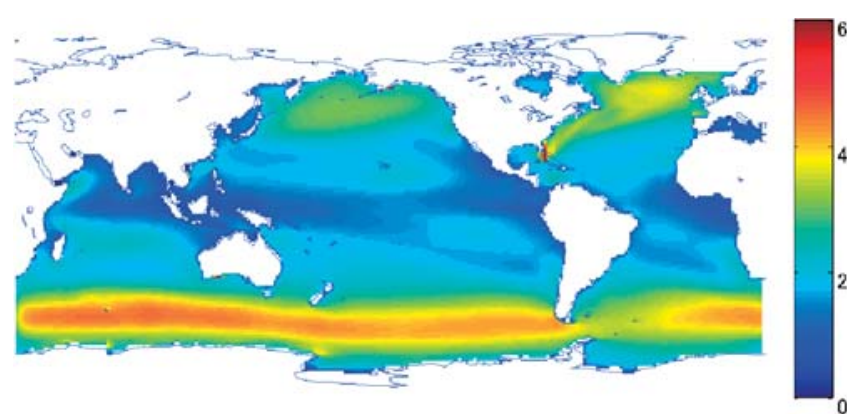

Figure 2. Period averaged $\bar{H}_{S}$

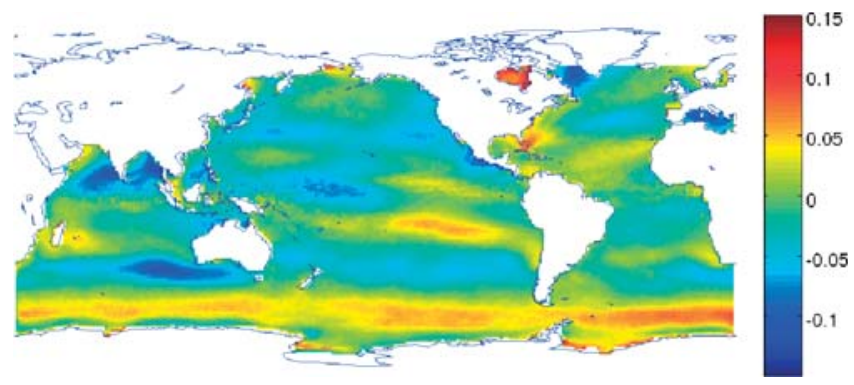

Figure 3. Difference of $\bar{H}_{s}$ between future minus present climate normalized by present climate

approximately. The eastern offshore area of Japan in the Pacific Ocean belongs to this decreased region and is expected to decrease by $5-10 \%$ in the future. On the other hand, the future wave height in the Antarctic Ocean will be increased $6-9 \%$ which corresponds to more than a $0.2 \mathrm{~m}$ increase of averaged wave height. Similar trends to the Antarctic Ocean can be observed in the Bering Sea and the Hudson Bay in the northern hemisphere. These changes are caused by the Ferrel cell movement to the polar areas.

To summarize the characteristics of averaged wave height change in the future, there is a clear latitude dependence. Both positive and negative future wave climate changes are possible depending on the latitude and region. This result shows that the future daily wave climate will have a lower mean wave height in the middle latitudes, and a higher mean wave height in the high latitudes and equator areas. These large scale changes of wave climate are caused by the global scale pattern changes of atmospheric pressure or wind field. Therefore, the discussion of regional wave climate change is necessary for the daily wave climate dependent process (i.e. beach process). In addition, the global scale pattern changes of $\bar{H}_{S}$ from the present to future climate is similar to $U_{10}$ (Mori et al., 2009) but there are significant differences in the detail on a regional scale.

\section{Extreme wave climate change}

The quantitative measure of extreme condition is arbitrary and is sensitive to the choice of parameters. General discussion should be conducted to compare with the extreme value distribution or probability density functions of targets. Figure 4 shows the spatially-averaged cumulative distribution of $H_{S}$ over the $99 \%$ value and up to its maximum in four areas. The Antarctic Ocean indicates the latitude range of $70^{\circ} \mathrm{S}-40^{\circ} \mathrm{S}$ and longitude range of $0-360$, the Southern Indian Ocean indicates the latitude range of $40^{\circ} \mathrm{S}-10^{\circ} \mathrm{S}$ and longitude range of 15-90, the south of Japan in the Pacific Ocean indicates the latitude range of $25^{\circ} \mathrm{N}-35^{\circ} \mathrm{N}$ and longitude range of 100-130, and the east of Japan in the Pacific Ocean indicates the latitude range of $35^{\circ} \mathrm{N}-45^{\circ} \mathrm{N}$ and longitude range of 115-140, respectively. The mean $H_{s}$ shown in Figure 2 corresponds to $0.5 \times 10^{-1}$ which is out of range in Figure 4. Both the cumulative distributions of $H_{S}$ in the present and future climates in the Antarctic Ocean and the east of Japan are quite similar and their maximum heights are about $16 \mathrm{~m}$. On the other hand, the future cumulative distributions in the Southern Indian Ocean and the south of Japan in the Pacific Ocean side are different from the present climate. The differences of distributions between the present and future conditions are significant and these differences are departed from the probability of $10^{-2}-10^{-3}$. The future spatial averaged maximum $H_{S}$ in these areas are 0.5 meters and 3 meters larger than that of present climate, respectively. The extreme wave condition in the south of Japan on the Pacific Ocean side will be increased, although the mean $H_{S}$ in this area will be decreased. The future cumulative distributions of $U_{10}$ in these areas show similar deviations from the present climate but the differences in $H_{s}$ are much larger than that of $U_{10}$. The wind stress to the wave energy is proportional to $U_{10}^{2}$ and therefore the extreme wave climate is more sensitive than that of wind climate. Although, the averaged wave climate condition depends on the global scale atmospheric circulation change as shown in Figure 2, the deviation of future wave condition in these areas are mainly influenced by tropical cyclones. The extreme waves induced by the tropical cyclones are very sensitive to the cyclone tracks and statistically unstable in the 25 years of data. Future investigation will therefore be required to verify these results quantitatively.

Finally, Figure 5 shows spatially averaged characteristic properties of $H_{s}$ for several oceans. The blue, green and red colored bars are the temporal-spatially averaged mean, averaged top 10 value and extreme index (EI) of $H_{s}$, respectively. The averaged top 10 value indicates the characteristics extreme value computed as the averaged top 10 value of cumulative distribution of $H_{S}$ (i.e. Figure 4) to avoid statistical sensitivity. The EI indicates the averaged top 10 value divided by its mean value, and it corresponds to the ratio of extreme value to mean value. The area averaged mean $H_{S}$ will be slightly increased in the Antarctic Ocean but will be decreased significantly in the Northern 


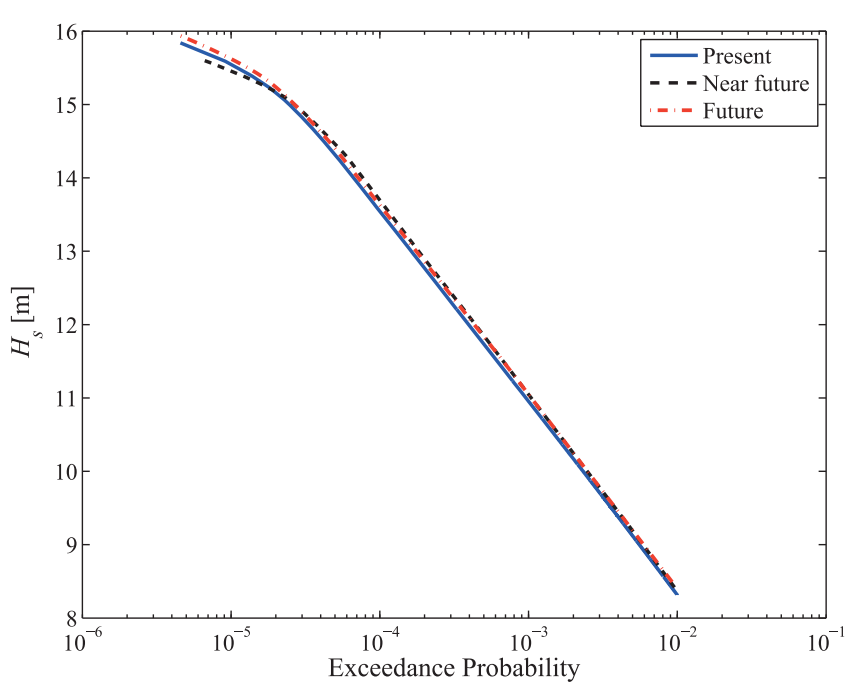

(a) Antarctic Ocean

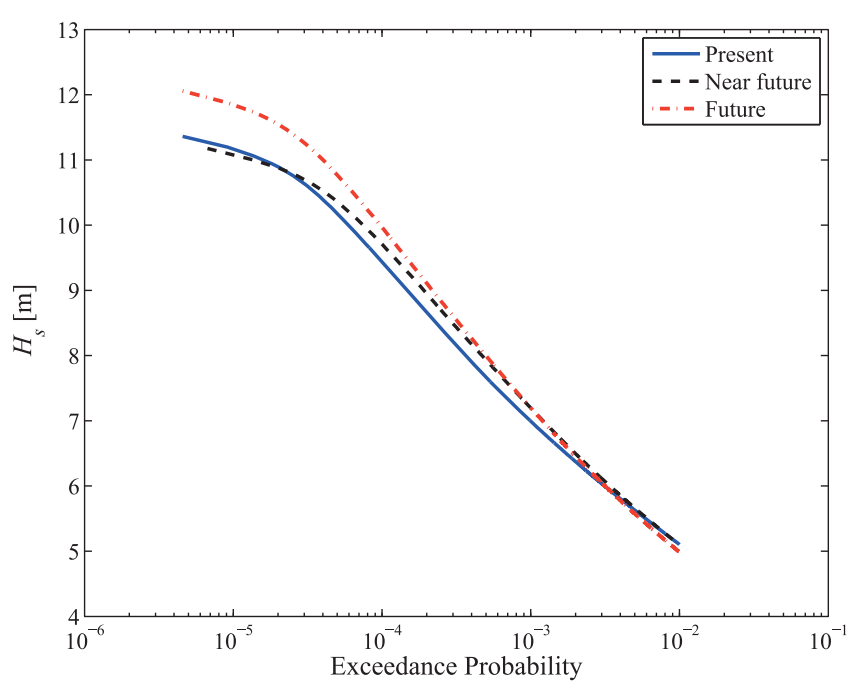

(b) Southern Indian Ocean

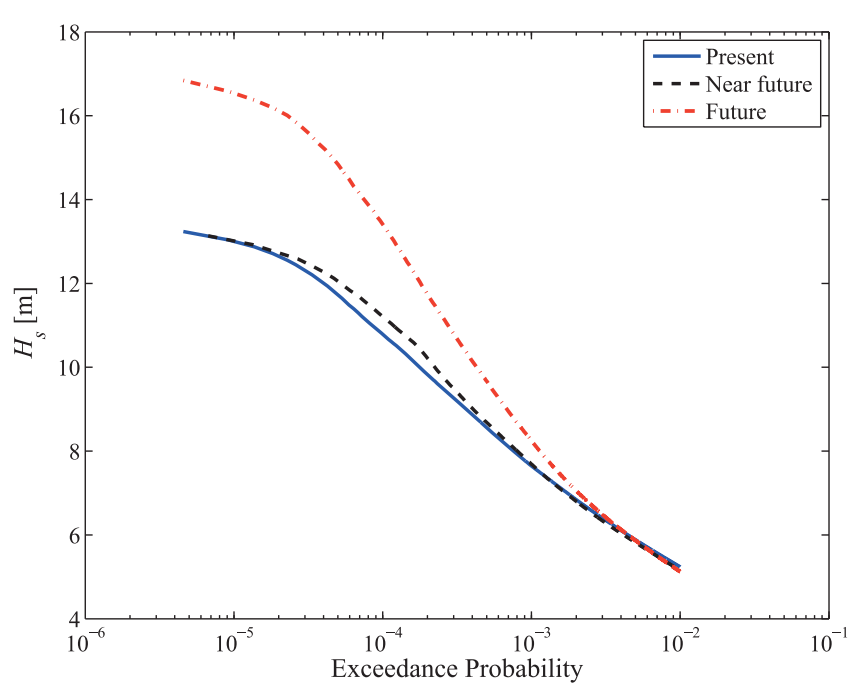

(c) South of Japan

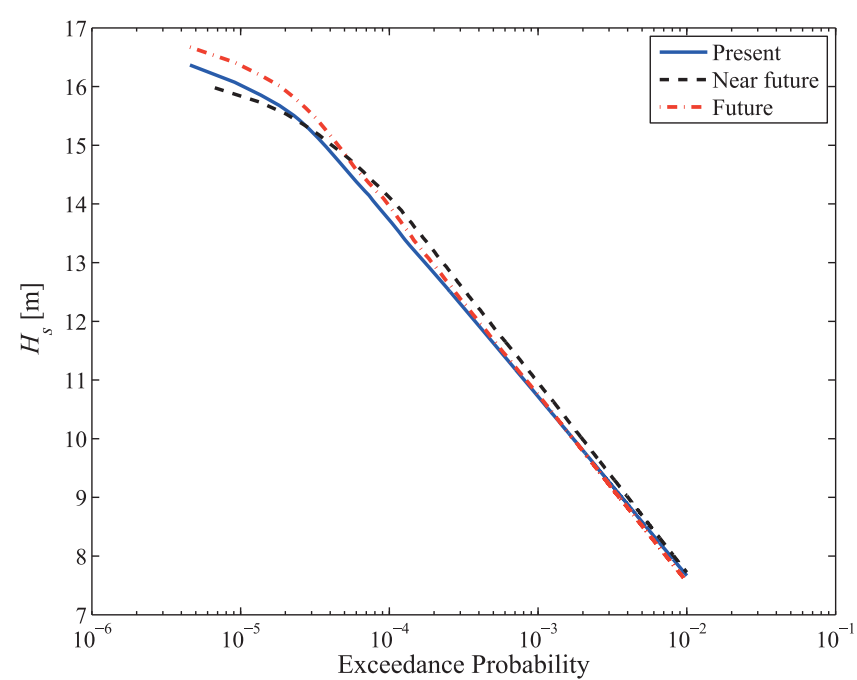

(d) East of Japan

Figure 4. Cumulative distribution of $H_{S}$ over $99 \%$

Pacific Ocean. The other areas will be slightly decreased but changes are not significant. On the other hand, the averaged top 10 values will be decreased in the Antarctic Ocean but will be increased in the Northern Pacific Ocean. This inverse relation is due to tropical cyclone effects. The MRI-JMA AGCM model produces intense tropical cyclones in the West Pacific Ocean. Therefore, the future extreme wave condition in the Northern Pacific Ocean, especially in the area near Japan, will become more severe than the present climate. In addition, due to the decreased mean $H_{s}$ in the future climate in this area, the future EI of $H_{s}$ will be significantly increased in comparison with the present climate. Both the global scale circulation change and the tropical cyclone changes are important for the projection of future wave climate change.

\section{CONCLUSION}

This study projected the future ocean wave changes based on the projections of the high-resolution atmospheric general circulation model and the global wave model. Based on the GCM and global wave model computations, the following expected future wave climate changes from the present were clearly shown.

The wave climate changes depend on the regions being negatively or positively changed. The mean waves will be increased at both the middle latitudes and also in the Antarctic ocean, and decreased at the equator. The sea off the coast of Japan belongs to the slightly decreased region where the mean winds and waves are decreased 5-10\% from those in the present climate. On the other hand, the extreme waves due to tropical cyclones will be increased. These results show that the future wave climate changes to lower mean and higher maximum wave heights in the middle latitudes, and higher mean and maximum wave heights in 


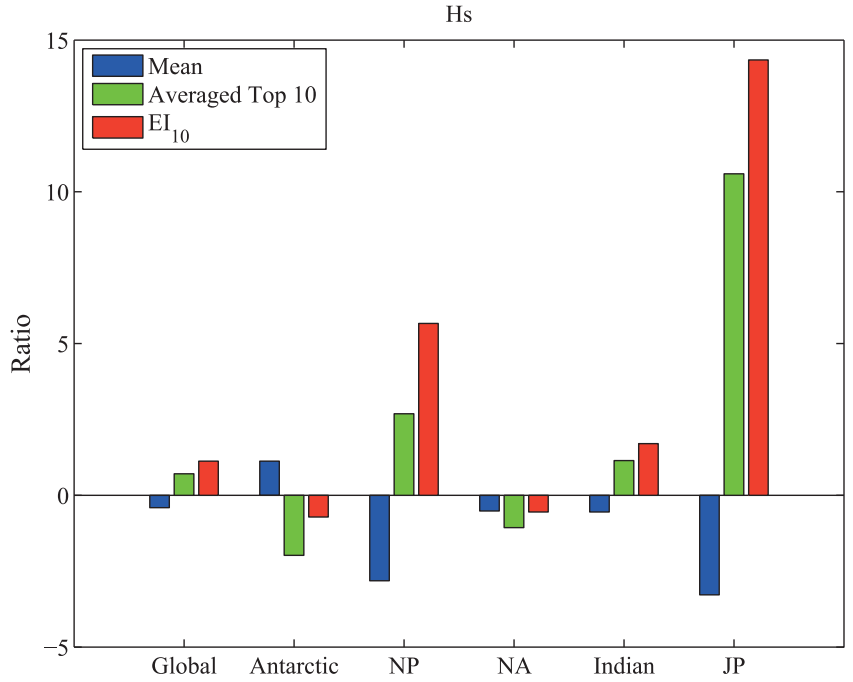

Figure 5. Spatially averaged mean, top 10 and EI of $H_{S}$ (NP: Northern Pacific, NA: Northern Atlantic, JP: Pacific Ocean near Japan)

the high latitudes. The future wave climate will experience both negative and positive change depending on the region. The influence of global scale pressure change and tropical cyclone change have different impacts to wave climate and should be considered separately.

\section{ACKNOWLEDGEMENTS}

This research was supported by the KAKUSHIN Program and the Kakenhi Grant-in-Aid of the Ministry of Education, Culture, Sports, Science, and Technology (MEXT).

\section{REFERENCES}

Booij N, Ris R, Holthuijsen L. 1999. A third-generation wave model for coastal regions. I- Model description and validation. Journal of Geophysical Research 104(C4): 7649-7666.

Church J, White N. 2006. A $20^{\text {th }}$ century acceleration in global sea-level rise. Geophysical Research Letters 33(1): L01602. doi:10.1029/2005GL024826.

Hemer M, Church J, Swail V, Wang X. 2006. Coordinated global wave climate projections. Atmosphere-Ocean Interactions 2: $185-218$.

IPCC. 2007. Climate Change 2007: The Physical Science Basis. Contribution of Working Group I to the Fourth Assessment Report of the Intergovernmental Panel on Climate Change, Solomon S, Qin D, Manning M, Chen Z, Marquis M, Averyt KB, Tignor M, Miller HL (eds.). Cambridge University Press: Cambridge, UK. 996 pp.

Kakushin. 2007. Innovative program of climate change projection for the 21st century, Japan. http://www.kakushin21.jp/. [December 3, 2009].

Kitoh A, Ose T, Kurihara K, Kusunoki S, Sugi M, KAKUSHIN Team-3 Modeling Group. 2009. Projection of changes in future weather extremes using super-high-resolution global and regional atmospheric models in the kakushin program: Results of preliminary experiments. Hydrological Research Letters 3: 49-53. doi:10.3178/hrl.3.49.

Mori N, Yasuda T, Iwashima R, Tom T, Mase H, Oku Y. 2009. Impact of global climate change on wave climate. Coastal Dynamics 2009, No. 135. doi:10.1142/97898142824750134.

Wang X. Swail V. 2002. Trends of Atlantic wave extremes as simulated in a 40-yr wave hindcast using kinematically reanalyzed wind fields. Journal of Climate 15(9): 1020-1035.

Wang X. and Swail V. 2006. Historical and possible future changes of wave heights in Northern Hemisphere oceans. AtmosphereOcean Interactions 2: 185-218.

Yasuda T, Mase H, Takada R, Kim S, Mori N, Oku Y. 2009. Evaluation of Typhoons due to Global Warming and Storm Surge Simulations by Using the General Circulation Model Outputs. In Proceedings of 33rd IAHR Congress 11370: 8 pp.

Zhang K, Douglas B, Leatherman S. 2004. Global warming and coastal erosion. Climatic Change 64(1): 41-58. 